\title{
The Management of Upper Urinary Tract Calculi in Spinal Cord Damaged Patients
}

\author{
B. P. Gardner, M.A., B.M., B.CH, M.R.C.P., F.R.C.S., ${ }^{1}$ K. F. Parsons, \\ M.B., Ch.B., F.R.C.S.E., F.R.C.S., ${ }^{2}$ B. M. Soni, M.B.B.S., M.S. ${ }^{3}$ and K. \\ R. Krishnan, M.B.B.S., F.R.C.S.E. ${ }^{4}$ \\ ${ }^{1}$ Senior Registrar, ${ }^{3}$ Registrar, ${ }^{4}$ Director Mersey Regional Spinal Injuries Centre, \\ Southport, Merseyside. ${ }^{2}$ Consultant Urological Surgeon, Royal Liverpool Hospital, \\ Liverpool, U.K.
}

\section{Summary}

The management of upper urinary tract calculi in 49 patients in the Mersey Regional Spinal Injuries Centre was reviewed retrospectively. Morbidity in nine patients was increased by either delay in operative intervention (5 cases) or inadequate follow up evaluation ( 4 cases). Earlier active treatment using modern endourological techniques and lithotripter technology is encouraged. A clinical algorithm incorporating these new techniques is shown.

Key words: Spinal Cord Injury; Calculi; Upper Urinary Tract; Management; Algorithm.

\section{Introduction}

Upper urinary tract calculi are an important source of morbidity in spinal cord damaged patients. The presentation, investigation and treatment of these patients at the Mersey Regional Spinal Injuries Unit is described.

In recent years there had been a significant change in the general management of stones, incorporating modern endourological and lithotripter technology (Segura, 1984). The ease of access to the collecting system by percutaneous puncture allows ready intrarenal manipulation and stone extraction. Modern percutaneous lithotripters, either ultrasonic or electrohydraulic, can disintegrate most calculi speedily and without morbidity (Segura et al., 1983; Lee et al., 1985; Wickham et al., 1983; Elder et al., 1984; Clayman et al., 1983). The extracorporeal lithotripter, even though not readily accessible yet to patients from spinal cord injury centres, can potentially be used for the treatment of calculi in these patients (Chaussy et al., 1983, 1984). Rigid ureterorenoscopy allows access to the upper ureter for endoscopic extraction of calculi and this lowers the threshold for intervention for high ureteric calculi (Huffman et al., 1983; Watson et al., 1983; Ford et al., 1983). 
This study defines the incidence of upper tract calculi in our patients and relates it to the potential use of the new technology.

\section{Patients and Methods}

The management of all the spinal cord damaged patients who have been regularly assessed at the Mersey Regional Spinal Injuries Centre was retrospectively reviewed. Data was analysed on patients with upper tract calculi using a DBASE II database file in a Sirius computer. Patients who had voluntarily defaulted from the follow up programme were excluded from the study.

\section{Results}

Eight hundred and nineteen spinal cord damaged patients were regularly assessed at the Mersey Regional Spinal Injuries Centre over a 37-year period. Forty-nine patients, of whom 41 were male and eight female, had upper urinary tract calculi. This sex distribution reflects the ratio of males to females at the centre.

The time from injury to initial presentation of the stone is shown in Figure 1.

The relationship between the neurological level and upper tract calculi is shown in Figure 2. The neurological level in all patients treated in this centre is also indicated for comparison.

The initial mode of presentation is indicated in Table 1 . In 78 per cent of patients the stones were discovered at routine follow up radiographic evaluation.

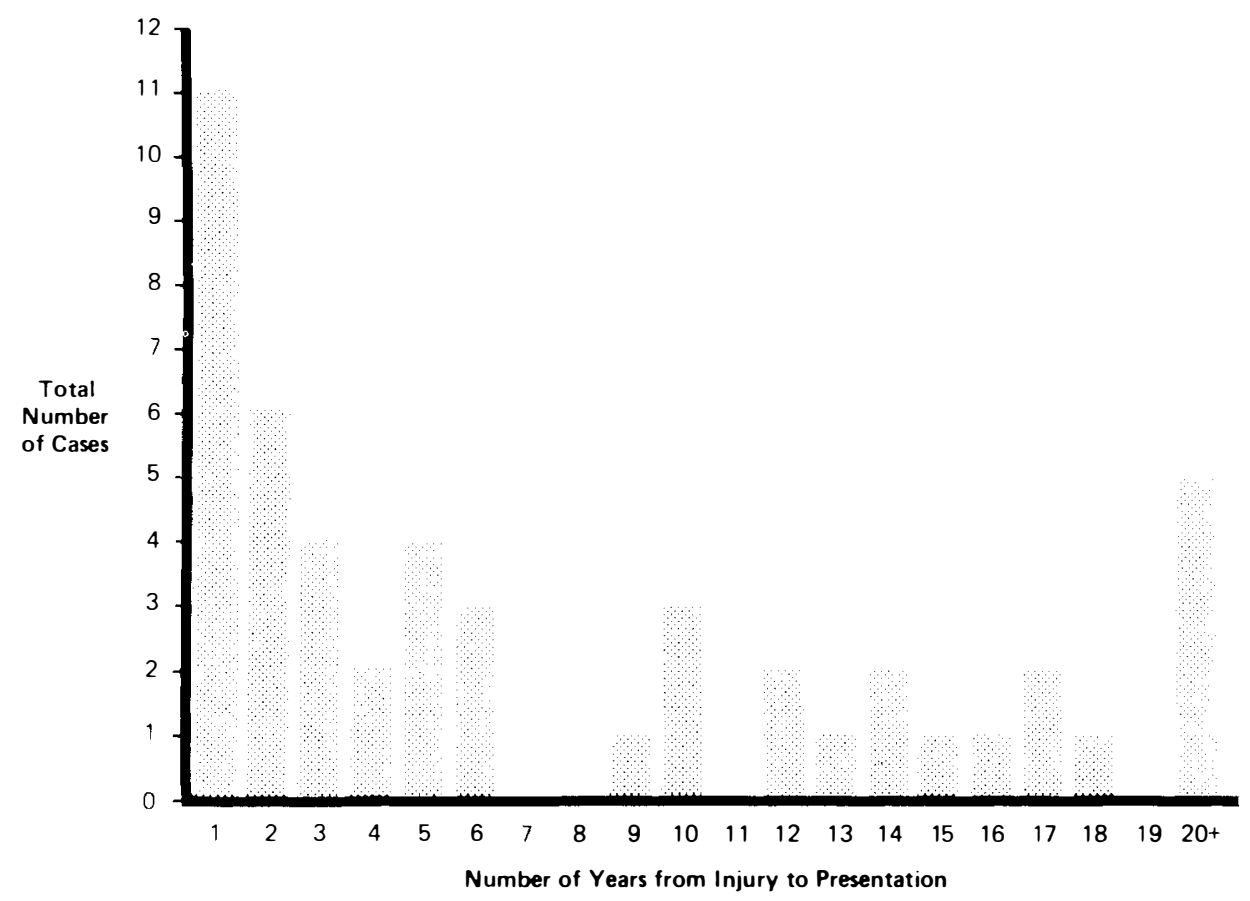

Figure 1. Number of years from injury to presentation of upper urinary tract calculi. 


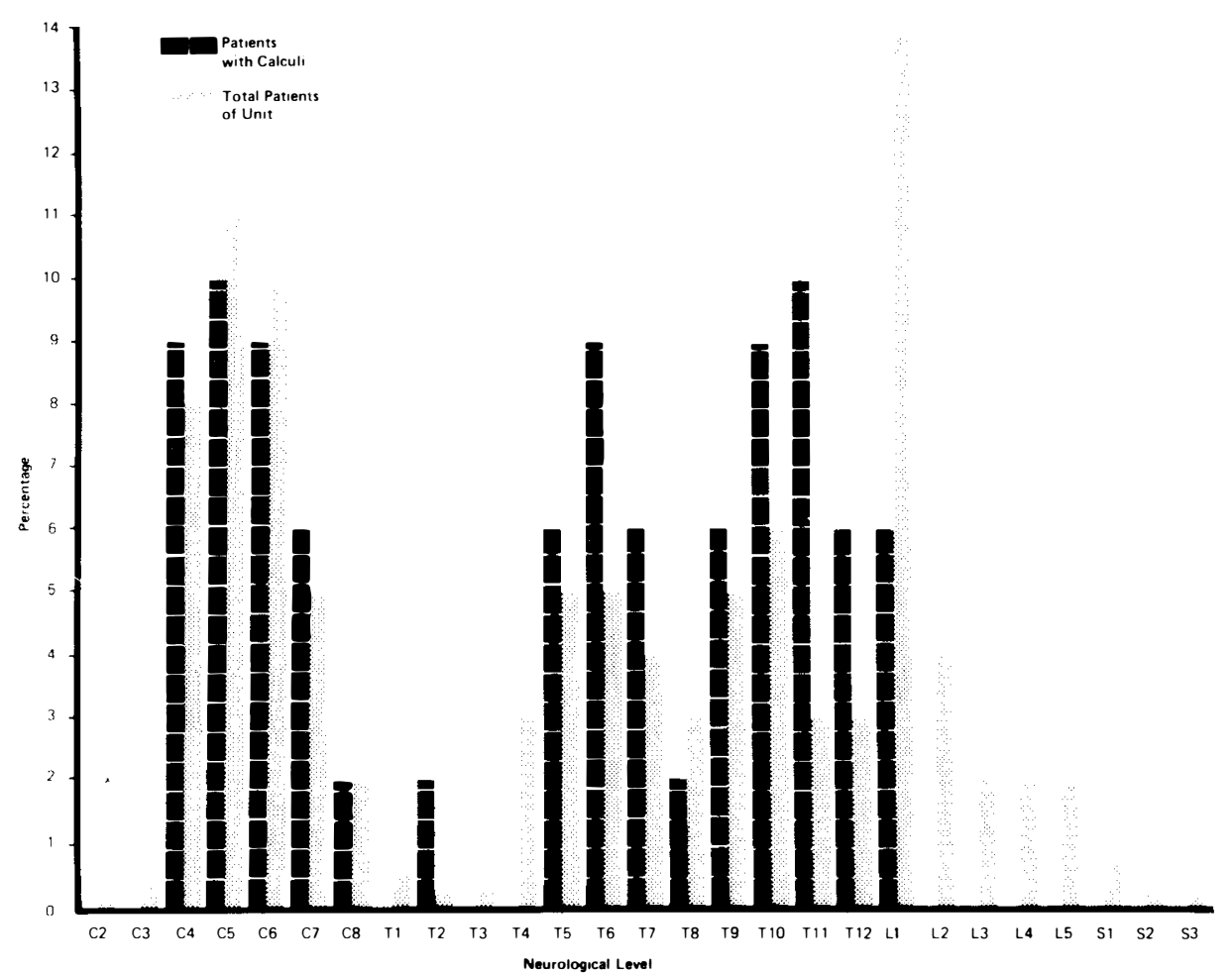

Figure 2. The neurological level of patients with upper tract calculi combined with the neurological level of all patients treated at the Mersey Regional Spinal Injuries Centre.

Table 1 Initial presentation

Asymptomatic- at routine IVU

Recurring U.T.I.

Renal or ureteric pain

Hypertension

Table 2 Symptoms and Signs at initial presentation

\begin{tabular}{ll}
\hline Recurring urinary infection & 8 \\
Ureteric or renal pain & 5 \\
Increased spasms & 1 \\
Hypertension & 1 \\
Haematuria & 1
\end{tabular}

Pain was not a feature in any patient with a complete lesion above T11. However, many patients with lesions at T11 or below had 'silent' calculi.

Symptoms and signs attributable to the calculi at initial presentation are shown in Table 2.

Biochemical assessment failed to reveal any examples of metabolic abnormality, although two patients had transient hypercalcaemia.

The radiographic findings are shown in Table 3. The majority of calculi were 
Table 3 Radiographic findings

\begin{tabular}{lr}
\hline Parenchymal & 6 \\
Small calyceal & 17 \\
Unilateral staghorn & 6 \\
Bilateral staghorn & 4 \\
Pelvis & 6 \\
Multiple unilateral & 6 \\
Multiple bilateral & 7 \\
Upper ureteric & 6 \\
Lower ureteric & 9 \\
Radiotranslucent & 2
\end{tabular}

Table 4 Complications of upper urinary tract calculi

\begin{tabular}{ll}
\hline Infection & $=21$ \\
Obstruction & $=10$ \\
Temporary loss of some renal function & $=4$ \\
Permanent loss of some renal function & $=15$ \\
Hypertension & $=1$ \\
\hline
\end{tabular}

Table 5 Initial treatment

\begin{tabular}{ll}
\hline Observe-repeat IVU in 1 year & $=31$ \\
Nephrectomy & $=1$ \\
Extracorporeal shock wave lithotripsy (ESWL) & $=0$ \\
Percutaneous extraction & $=3$ \\
Pyelolithotomy & $=6$ \\
Ureteroscopic extraction & $=2$ \\
Ureterolithotomy & $=6$ \\
Dormia basket extraction & $=3$
\end{tabular}

small and single but a number of patients had multiple or bilateral calculi at initial presentation.

The complications caused by the upper tract calculi are indicated in Table 4.

The initial treatments employed are shown in Table 5. Over 60 per cent were treated conservatively in the first instance. In nine patients, the outcome was adversely affected by the management adopted. In five of these, earlier operative intervention would probably have reduced morbidity whilst in the other four, more frequent regular review might have improved the outcome.

\section{Discussion}

This study suggests that the aetiology of stones in spinal cord damaged patients is different in some respects to that pertaining in the general population and there are a number of factors which highlight this difference. Firstly, the general male to female sex ratio in patients with stones is $2: 1$ whereas in this series of spinal cord damaged patients with stones the sex ratio of $5: 1$ males to females closely approximates to that of the unit as a whole. Secondly, there were no patients with hyperparathyroidism contrasting with a 5 per cent incidence in other stone 
formers. Thirdly, the incidence of stones in this series ( 6 per cent) is several times greater than that in the general population. The incidence of stones at different neurological levels does not correspond with the incidence of spinal cord damage at these levels (Fig. 2). The complete absence of stones below L1 may be significant. Finally, radiotranslucent stones usually account for 10 per cent of calculi in the general population but only 4 per cent of stones in this series were of this variety.

Upper urinary tract calculi are relatively uncommon in spinal cord damaged patients but are important because of their potential serious consequences (Table 4). The results stress the importance of regular radiographic assessment in ensuring early diagnosis. Although many calculi are diagnosed within 2 years of injury, over 69 per cent present after this time, indicating that recumbency is not the sole aetiological factor. At no stage does the risk of stones disappear (Fig. 1). Over 78 per cent of stones present asymptomatically (Table 1) and even when the neurological level is at T11 or below, stones may be 'silent'. Some patients develop large calculi with great rapidity, indicating the hazards of infrequent review.

The intital treatment that was employed in each patient in this series was conservative in over 60 per cent of cases. This approach was often adopted because of potential hazards due to either operative difficulties, such as ankylosing spondylitis restricting renal access, or possible postoperative morbidity, especially in tetraplegic patients with borderline respiratory function. However, five patients managed using a 'wait and see' approach subsequently suffered from either serious infection or significant deterioration in renal function.

The indications in this centre for active intervention for stones in spinal cord injured patients are shown in Table 6 . Reticence regarding active intervention is

Table 6 Indications for active intervention

1. Obstruction-actual or impending

2. Recurring infection

3. Renal destruction-actual or threatened

4. Increasing size of calculus

5. Potential poor compliance in follow-up programme

no longer acceptable in the light of the modern endourological techniques and lithotripter technology (Marberger et al., 1985; Brannen et al., 1985; Mayo et al., 1985; Bush et al., 1984). However, the precise place for these new treatments requires definition because of problems of management specific to spinal cord injured patients. Transurethral endoscopic and percutaneous nephroscopic procedures can be safely carried out in spinal cord injury centres, but extracorporeal lithotripsy demands that the patient be managed by a different team in a different centre. The impaired cardiovascular and respiratory functions, vulnerable skin and propensity to spasms of many spinal cord damaged patients may render extracorporeal lithotripsy inappropriate (Weber et al., 1984; Finlayson et al., 1984).

The current policy that is being adopted in this centre is indicated in Figures 


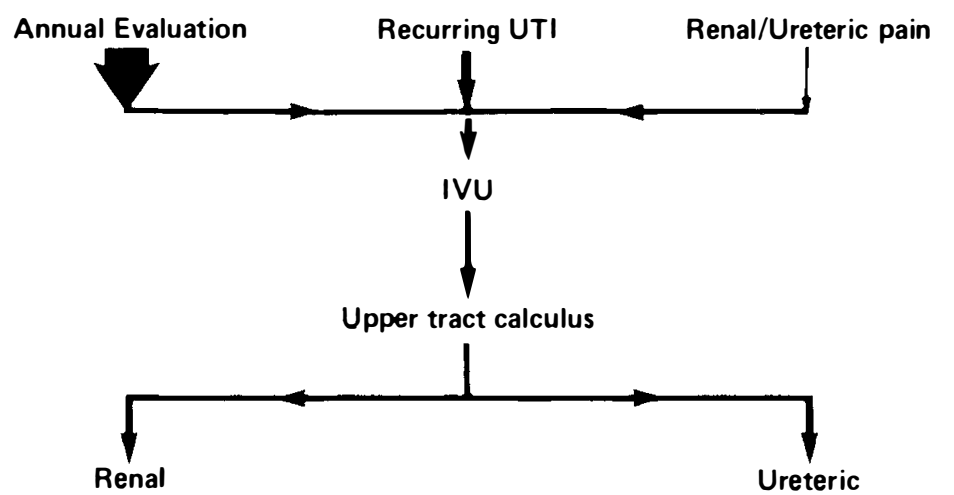

Figure 3. The presentation of upper urinary tract calculi in spinal cord injured patients.

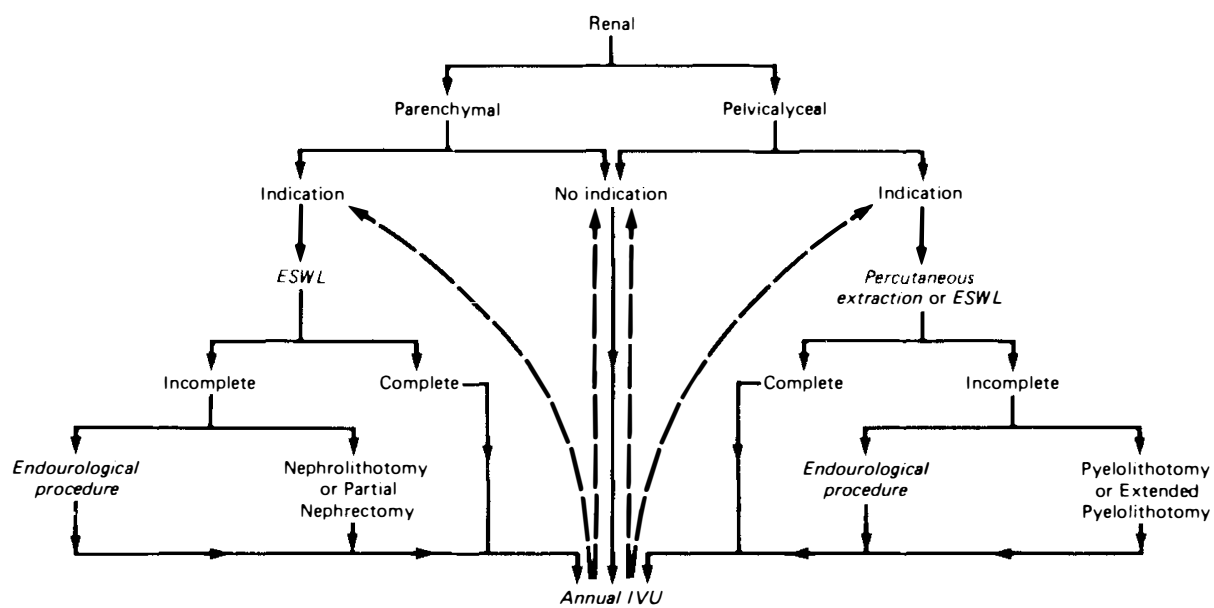

Figure 4. The management of renal calculi in spinal cord damaged patients.

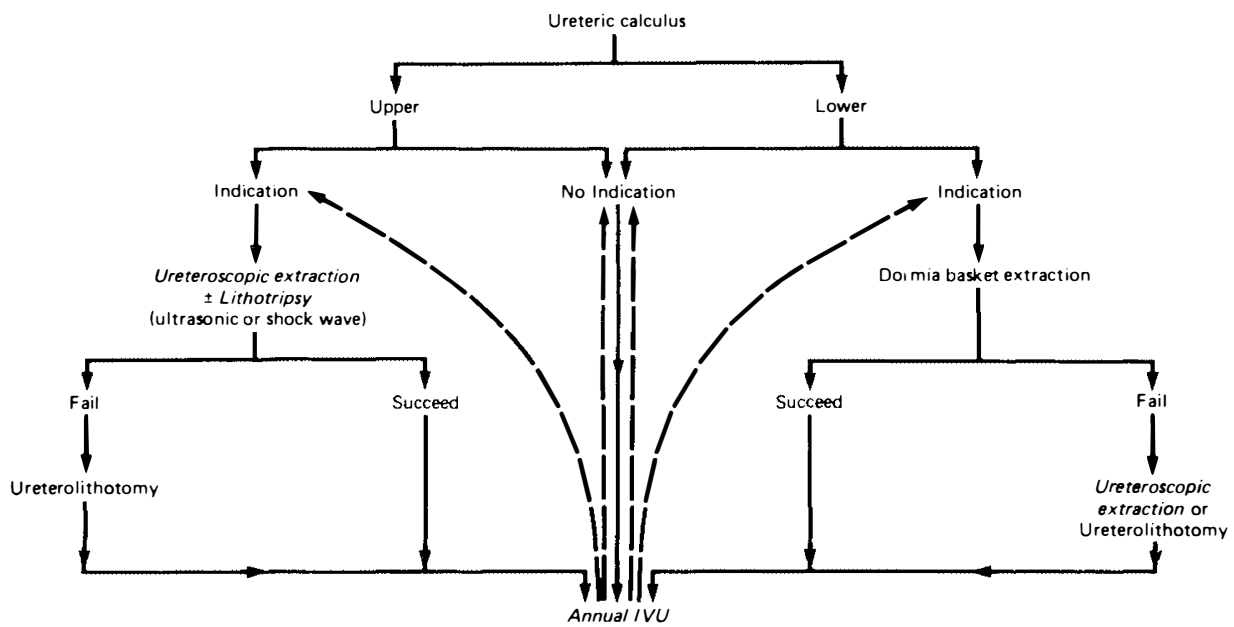

Figure 5. The management of ureteric calculi in spinal cord damaged patients. 
3, 4 and 5. It is recognised that this algorithm may require modification in the light of further developments and experience, but it is hoped that the combination of the modern techniques and regular upper tract evaluation will serve to minimise the morbidity caused by stones.

\section{Conclusion}

The morbidity caused by upper urinary tract calculi in spinal cord damaged patients may be reduced by regular follow-up evaluation and active intervention when indicated using modern endourological techniques and lithotripter technology.

\section{Acknowledgements}

We acknowledge the contributions of Mr J. C. Ross, Mr N. O. K. Gibbon and Mr R. M. Jameson in the urological management of the patients of the Mersey Regional Spinal Injuries Centre.

This paper was presented at the Second Euro Mediterranean Meeting of Paraplegia in Toledo, Spain in April, 1985.

\section{Résumé}

On a revu retrospectivement le traitement des calculs des voies urinaires supérieures chez 49 malades dans le Centre Régional de Lésions Vertébrales du Mersey. La morbidité chez neuf malades a été augmentée soit par un retard d'intervention opérative ( 5 cas) soit par une évaluation d'étude ultérieure insuffisante $(4 \mathrm{cas})$. On encourage actuellement un traitement actif entrepris plus tôt, à l'aide des technique endo-urologiques modernes et de la technique de lithotriptère. On montre un algorhtthme clinique qui incorpore ces techniques nouvelles.

\section{Zusammenfassung}

Man hat die Behandlung von Steinen der Oberharnwege bei 49 Patienten im Mersey-Kreiszentrum für Rückengratverletzungen zurückblickend durchgesehen. Die Morbidität bei 9 Patienten ist entweder durch Verzögerung mit operativem Einriff (5 Fälle) oder durch ungenügende Nachbeobachtungsauswertung ( 4 Fälle) vergrössert worden. Eine frühzeitigere Anwendung ven aktiver Behandlung mit Hilfe von modernen endourologischen Techniken und von Lithotriptertechnik wird heutzutage gefördert. Man zeigt einen klinischen Algorhythmus, der diese neuen Technịen einschliesst.

\section{References}

Brannen GE, Bush WH, Correa RJ, et al. 1985 Kidney stone removal: percutaneous versus surgical lithotomy. Journal of Urology 133 (Pt. 1):6-12.

Bush WH, Brannen GE, Gibbons RP, et al. 1984 Radiation exposure to patient and urologist during percutaneous nephrostolithotomy. Journal of Urology 132:1148-1152.

Chaussy C, Schmiedt E. 1984 Four year's experience with extracorporeal shock wave lithotripsy (ESWL) in Munich. Abstracted. Journal of Urology 131(Pt. 2):264A.

Chaussy C, Schmied E. 1983 Shock wave treatment for stones in the upper urinary tract. Urologic Clinics of North America 10:743-750.

Clayman RV, Surya V, Miller RP, et al. 1983. Percutaneous nephrolithotomy. An approach to branched and staghorn renal calculi. Journal of the American Medical Association 250:73-75.

ELDER JS, GibBONS RP, BUSH WH. 1984. Ultrasonic lithotripsy of a large staghorn calculus. Journal of Urology 131:1152-1154.

Finlayson B, Thomas WC JR. 1984. Extracorporeal shock-wave lithotripsy. Annals of Internal Medicine 101(3):387-389. 
Ford TF, WATsON GM, WICKhAM JEA. 1983. Transurethral Ureteroscopic Retrieval of Ureteric Stones. British Journal of Urology 55:626-628.

HuffMAN JL, BAgley DH, Schoenberg HW, LyON ES. 1983. Transurethral removal of large ureteral and renal pelvic calculi using ureteroscopic ultrasonic lithotripsy. Journal of Urology 130:31-34.

LEE WJ, LoH G, SMITH AD, et al. 1985. Percutaneous extraction of renal stones: experience in 100 patients. AJR 144:451-455.

Marberger M, StaCkL W, Hruby W, Kroiss A. 1985. Late sequelae of ultrasonic lithotripsy of renal calculi. Journal of Urology 133(2):170-173.

MAYo ME, KRIEGER JN, RUDD TG. 1985. Effect of percutaneous nephrostolithotomy on renal function. Journal of Urology 133:167-169.

Segura JW. 1984. Endourology. Review Article. Journal of Urology 132:1079-1084.

Segura JW, Patterson DE, LeRoy AJ, et al. 1983. Percutaneous lithotripsy. Journal of Urology 130:1051-1054.

Watson GM, Wickham JEA, Mills TN, et al. 1983. Laser Fragmentation of Renal Calculi. British Journal of Urology 55:613-616.

Weber W, Chaussy C, Madler C, et al. 1984. Cardiocirculatory changes during anesthesia for extracorporeal shock wave lithotripsy. Journal of Urology 131(Pt. 2):246A.

Wickham JEA, Kellett MJ, Miller RA. 1983. Elective percutaneous nephrolithotomy in 50 patients: an analysis of the technique, results and complications. Journal of Urology 129(5):904-906. 